\section{BIMBINGAN BELAJAR BAHASA INGGRIS \\ BAGI ANAK USIA SEKOLAH DASAR (6-12 TAHUN) \\ DI DESA SEMANGAT DALAM RT.31HANDIL BHAKTI}

Dewi Rosaria dan Hartatya Novika

Fakultas Keguruan dan Ilmu Pendidikan, Universitas Islam Kalimantan MAB

Email: dewi22041984@gmail.com

\begin{abstract}
This community service activity was in the form of English tutoring at Semangat Dalam village RT.31Handil Bhakti. The objectives are 1) to know the proper way to provide English tutoring for primary school age children in Semangat Dalam village, 2) to know that Englis tutoring is effective for primary school age children. This activity used 3 (three) methods, such as lectures, discussion, and games. The results of this tutoring activity are 1) it is known that primary school age children (6-12 years of age) were more enthusiastic and they were able to follow and understand the material when team taught them using games method in particular by singing songs related to the material.They become more confident to introduce themselves using English in front of their friends. 2) tutoring is effective enough to help primary school age children in Semangat Dalam village to increase their knowledge and understanding of English lessons, as well as increase their confidence in using English.
\end{abstract}

Keywords: tutoring, English tutoring, primary school age children

\section{PENDAHULUAN}

Pada era sekarang ini bahasa Inggris dikenal juga sebagai bahasa internasionalyang begitu sangat diperlukan. Masyarakat semakin dituntut untuk mampu berbahasa Inggris baik pasif maupun aktif.Keterampilan untuk menguasai bahasa Inggris ini ditunjang dengan adanya mata pelajaran bahasa Inggris yang sudah mulai dikenalkan di bangku sekolah, maupun lembaga-lembaga kursus ataupun bimbingan belajar bahasa Inggris yang sudah semakin menjamur di berbagai tempat, khususnya di perkotaan.

Pada umumnya, mempelajari bahasa seperti bahasa Inggris bagi anakanak usia Sekolah Dasar sangatlah bagus dikarenakan pada usia tersebut, kemampuan mereka dalam mempelajari suatu bahasa lebih cepat jika dibandingkan dengan anak yang sudah berusia di atas 12 tahun. Pada rentang usia 6-12 tahun itu kemampuan kognitif anak sedang berkembang dengan baik.

Adapun bimbingan belajar adalah merupakan proses pemberian bantuan atau pertolongan baik bagi 
individu maupun kelompok oleh seorang atau lebih pembimbing yang memiliki keahlian di bidang tersebut dalam menentukan pilihan, penyesuaian serta pemecahan masalah belajar yang berkaitan dengan perubahan tingkah laku sebagai akibat dari pengalaman, latihan maupun rangsangan.

Keputusan

untuk mengikutsertakan anak di lembaga kursus atau bimbingan belajar merupakan keputusan yang tepat bagi anak-anak. Di sanalah mereka bisa memperoleh ilmu kebahasaan yang lebih yang tidak sempat diajarkan oleh guru di sekolah. Akan tetapi, tidak semua anak bisa mengikuti les ataupun bimbingan belajar dikarenakan beberapa hal seperti salah satunya lingkungan tempat tinggal anak yang jauh dari pusat perkotaan.

Dengan melihat kendala tersebut, membuat tim pengabdian masyarakat merasa terpanggil untuk melakukan bimbingan belajar bahasa Inggris bagi anak usia Sekolah Dasar (6-12 tahun) yang berada di desa Semangat Dalam RT.31 Handil Bhakti yang mana desa Semangat Dalam berlokasi cukup jauh dari pusat kota Banjarmasin.

\section{Identifikasi dan Perumusan Masalah}

Berdasarkan pembahasan latar belakang permasalahan tersebut di atas, maka dapat diidentifikasi masalahnya yakni bahwa anak-anak usia sekolah dasar yang berada di lingkungan atau tempat tinggal yang jauh dari pusat kota merasa kesulitan untuk ikut belajar intensif di lembaga-lembaga kursus atau bimbingan belajar bahasa Inggris yang umumnya berada di pusat kota.

Adapun masalah tersebut dapat dirumuskan yakni sebagai berikut: (1) Bagaimana cara memberikan bimbingan belajar bahasa Inggris kepada anak usia sekolah dasar? (2) Apakah bimbingan belajar bahasa Inggris efektif bagi anak usia sekolah dasar tersebut?

\section{Tujuan dan Manfaat Kegiatan}

Adapun tujuan yang ingin dicapai dalam kegiatan ini adalah: (1) Untuk mengetahui cara yang tepat dalam memberikan bimbingan belajar bahasa Inggris bagi anak usia sekolah dasar. (2) Untuk mengetahui bahwa bimbingan belajar efektif bagi anak usia sekolah dasar di desa Semangat Dalam tersebut.

Kegiatan ini juga bermanfaat untuk membantu anak usia sekolah dasar menyesuaikan serta mengembangkan kemampuan dan ilmu 
pengetahuan bahasa Inggris mereka, melatih kepercayaan diri mereka dalam menggunakan Bahasa Inggris.

\section{KHALAYAK SASARAN}

Khalayak yang menjadi sasaran dalam kegiatan ini adalah anak-anak usia sekolah dasar (6-12 tahun) yang berada atau bertempat tinggal di desa Semangat Dalam RT.31 Handil Bhaktidengan jumlah peserta sekitar 16 orang anak berasal dari kelas 1-4 SD. Mereka adalah siswa-siswi Sekolah Dasar yang tidak mengikuti kursus ataupun bimbingan belajar bahasa Inggris di luarpelajaran bahasa Inggris yang didapat di sekolah.

\section{METODE}

Kegiatan pengabdian kepada masyarakat ini yang berupa bimbingan belajar bahasa Inggris dilaksanakan pada hari Minggu tanggal 18 Desember 2016 pada pukul 09.00 pagi sampai dengan pukul 12.00 siang. Pelaksanaan kegiatan bimbingan belajar bahasa Inggris ini adalah dengan menggunakan 3 (tiga) metode kegiatan yakni metode ceramah, tanya jawab, dan permainan. Dalam metode ceramah, tim menjelaskan tentang materi yang diajarkan dan anak-anak mendengarkan dengan saksama penjelasan dari tim guna memberikan pemahaman kepada mereka. Metode tanya jawab dilaksanakan untuk mengetahui sejauh mana pemahaman anak terhadap penjelasan yang didengar sebelumnya. Setelah itu tim juga menggunakan metode permainan.

\section{HASIL DAN PEMBAHASAN}

Kegiatan pengabdian kepada masyarakat ini memberikan banyak manfaat, wawasan dan pengetahuan serta pemahaman anak tentang belajar bahasa Inggris khususnya sesuai dengan materi yang disampaikan oleh tim yang mana hasil akhirnya anak-anak tersebut mampu memperkenalkan diri dalam bahasa Inggris dengan rasa percaya diri. Adapun kegiatan pengabdian kepada masyarakat khususnya bimbingan belajar bahasa Inggris ini mencapai hasil yang mengacu pada tujuan kegiatan yang telah dijelaskan di atas.

Untuk mengetahui cara yang tepat dalam memberikan bimbingan belajar bahasa Inggris bagi anak usia sekolah dasar

Anak-anak usia Sekolah Dasar (6-12 tahun) lebih antusias serta mampu mengikuti dan memahami materi pada 
saat tim mengajarkan dengan metode permainan khususnya dengan menyanyikan lagu yang berkaitan dengan materi (sing a song). Mereka menjadi lebih percaya diri untuk memperkenalkan diri menggunakan bahasa Inggris di depan temantemannya. Metode permainan cocok digunakan dalam mengajarkan anakanak usia Sekolah Dasar (6-12 tahun) karena pada usia tersebut memang biasanya metode belajar yang disukai anak adalah belajar sambil bermain.Mereka jadi lebih cepat memahami materi yang disampaikan. Hal ini berkaitan dengan apa yang dijelaskan oleh Wong dalam Supriyanto (2013) yakni anak usia sekolah dasar (6-12 tahun) merupakan masa dimana anak dapat memperoleh dasar-dasar pengetahuan untuk keberhasilan penyesuaian diri pada kehidupan dewasanya serta dapat memperoleh keterampilan tertentu.

Untuk mengetahui bahwa bimbingan belajar efektif bagi anak usia sekolah dasar di desa Semangat Dalam

Bimbingan belajar cukup efektif untuk membantu anak usia sekolah dasar di desa Semangat Dalam untuk menambah pengetahuan dan pemahaman mereka tentang pelajaran
Bahasa Inggris baik itu dari pelafalannya maupun penguasaan kosa kata yang telah diajarkan oleh tim, serta meningkatkan kepercayaan diri mereka dalam menggunakan bahasa Inggris. Hal ini terlihat ketika mereka mampu memperkenalkan diri dengan percaya diri di depan teman-temannya dengan menggunakan bahasa Inggris. Hasil yang menunjukkan bahwa bimbingan belajar ini cukup efektif dilaksanakan sejalan dengan beberapa pendapat yang menjelaskan tentang pengertian dari bimbingan belajar.

Anonymous (2007) menuliskan di perkuliahan.com, pengertian bimbingan adalah sebagai berikut:

a. Bimo Walgito: "Bimbingan adalah bantuan atau pertolongan yang diberikan kepada individu atau sekumpulan individu dalam menghindari atau mengatasi kesulitan-kesulitan di dalam kehidupannya, agar individu itu dapat mencapai kesejahteraan hidupnya".

b. Dewa Ketut Supardi: "Bimbingan adalah proses pemberian bantuan yang diberikan kepada seseorang atau sekelompok orang secara terusmenerus dan sistematis oleh 
pembimbing agar individu menjadi pribadi yang mandiri”.

c. Arthur J. Jones:" "bimbingan adalah bantuan yang diberikan oleh seseorang kepada orang lain dalam menentukan pilihan, penyesuaian dan dalam memecahkan masalah".

Selain itu, dijelaskan pula oleh Ahman \& Kartadinata (2007) bahwa pengertian bimbingan terdapat dalam Peraturan Pemerintah Nomor 28 Tahun 1990 tentang Pendidikan Dasar Bab X Pasal 25, yaitu:

(1) Bimbingan merupakan bantuan yang diberikan kepada siswa dalam rangka upaya menemukan pribadi, mengenal lingkungan dan merencanakan masa depan.

(2) Bimbingan diberikan oleh guru pembimbing.

Sedangkan pengertian belajar juga dijelaskan oleh para ahli dalam Anonymous (2007) di sebuah forum di internet perkuliahan.com yakni sebagai berikut:

a. Clifford T. Morgan \& Richaard A. King: Belajar didefinisikan sebagai perubahan tingkah laku yang relatif tetap yang terjadi sebagai hasil dari pengalaman atau latihan".

b. Muhibbin Syah: "Belajar adalah tahapan perubahan seluruh tingkah laku individu yang relatif menetap sebagai hasil dari pengalaman dan interaksi dengan lingkungan yang melibatkan proses kognitif".

c. Mustofa Fahmi: "Belajar adalah suatu perubahan di dalam tingkah laku yang dihasilkan dari rangsangan".

\section{FOTO KEGIATAN}

Anak-anak mendengarkan penjelasan materi dari tim (metode ceramah)
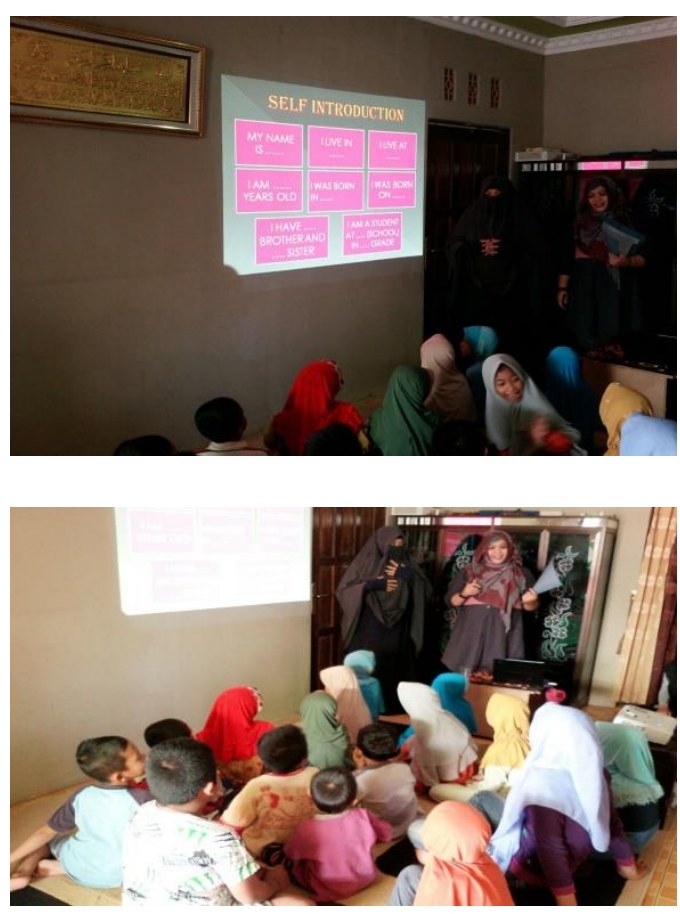

Anak-anak bernyanyi sambil memperagakan anggota tubuh (metode permainan)

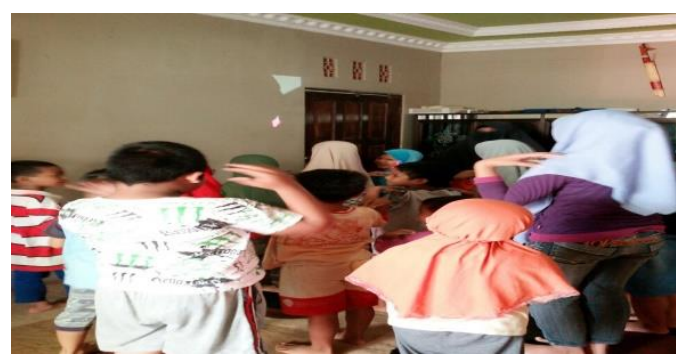


Anak-anak mengacungkan tangan pada waktu tim memberikan pertanyaan (metode tanya jawab)

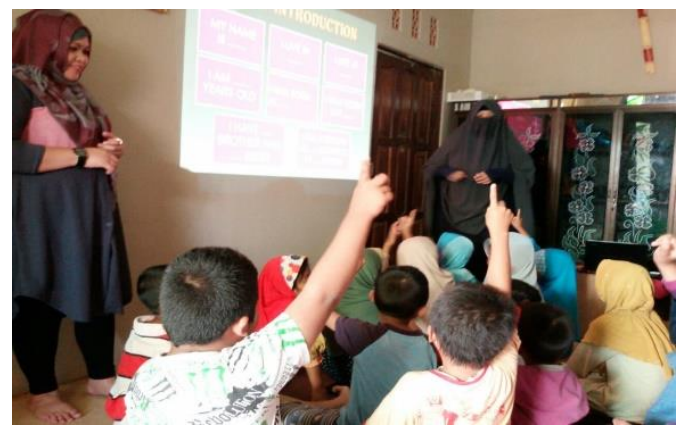

Salah satu dari mereka maju kedepan untuk mencoba belajar memperkenalkan diri dengan bahasa inggris
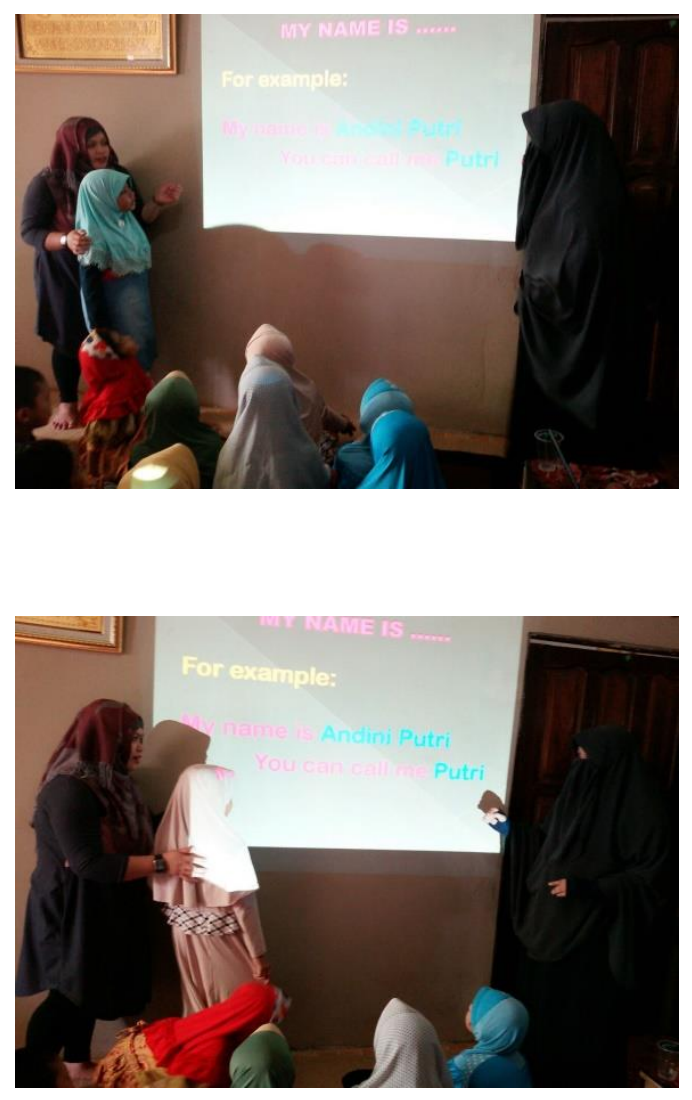

Anak-anak sangat antusias mengikuti

bimbingan belajar bahasa Inggris

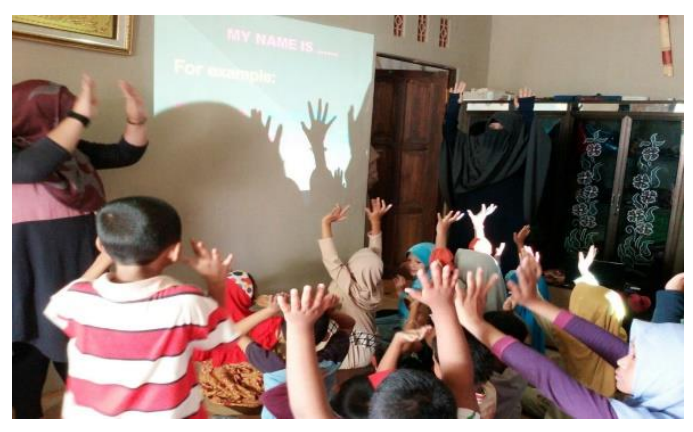

\section{KESIMPULAN}

Berdasarkan hasil kegiatan yang sudah dijelaskan di atas, dapat disimpulkan bahwa bimbingan belajar bahasa Inggris dapat membantu anakanak usia sekolah dasar di desa Semangat Dalam RT.31 Handil Bhakti yang tidak bisa ikut belajar di lembaga kursus ataupun bimbingan belajar bahasa Inggris dikarenakan lembaga kursus atau bimbingan belajar yang berada jauh di pusat kota. Anak-anak tersebut jadi lebih memahami pelajaran bahasa Inggris serta lebih meningkatkan kepercayaan diri mereka yang diajarkan dengan menggunakan metode permainan (belajar sambil bermain). Hal ini terlihat pada saat sesi akhir bimbingan mereka diminta untuk memperkenalkan diri dengan menggunakan bahasa Inggris, mereka bisa dengan percaya diri melakukannya. 
DAFTAR PUSTAKA

Ahman \& Kartadinata, S. (2007). Ilmu dan Aplikasi Pendidikan. Imperial Bhakti Utama.

Anonymous. (2012), Pengertian Bimbingan Belajar, Perkuliahan.com

http://www.perkuliahan.com/pengertian -bimbingan--belajar/ (dibuka kembali pada 24 November 2016)
Suparyanto. (2013), Sekilas tentang Anak Usia Sekolah, Blogger. http://drsuparyanto.blogspot.co.id/2013/0 5/sekilas-tentang-anak-usiasekolah.html//(dibuka kembali pada 24 November 2016) 